\title{
Analysis on the Characteristics of Chinese National Folk Sports Tourism Destination
}

\author{
YI Cuixia \\ School of Physical Education \\ Shaanxi Normal University \\ Xi'an 710062, China
}

\begin{abstract}
By using the literature material method, field survey method and other research methods, based on defining the national folk sports tourism destination, and by using multidisciplinary theory, we conclude and summarize our country folk sports tourism destination. It has the characteristics of complexity, scarcity, national and regional characteristics, cultural diversity, functional diversity features, reciprocal symbiosis, and the characteristics of tourist destination lifecycle.
\end{abstract}

Keywords- National Folk Sports; Tourism Destination; Characteristics

\section{INTRODUCTION}

Each concept has a specific generation and conditions of use, and there is no absolute limits one or the other. Based on the concepts of national folk sports, ethnic folk sports events, sports tourism destination, etc. summarize, which are based on the analysis of national folk sports tourism destination for a simple definition. Meanwhile, the use of multi-disciplinary theory is combining our national sporting events and tourist destinations folk fieldwork, summary, which summarized the basic characteristics of a series of national folk sports tourism destination, in order to provide a theoretical basis for further research and academics related to the author .

\section{DEFINING NATIONAL FOLK SPORTS TOURISM DESTINATION}

\section{A. National Folk Sports}

National Folk Sports in its emergence and development process have different researchers because they have a different understanding and awareness. National Folk Sports is a composite term, through the "nation", "folk" two qualifiers for the sports culture has been limited. It is expressed as: a nation or country the public in their daily life and activities directly created space has inherent ways and culture of sports culture. As a sports culture, that is carrying a value orientation nation, it is affecting a nation's way of life, reflecting the self-identity of a nation's cohesion. [1] It is an important part of national culture, and penetration with all levels of Chinese culture. Our numerous nationalities and ethnic folk sport have deep soil and extensive participation groups, the original ecology and regional identity; it has a very tough force and permanent vitality. But with the development of all areas of society, it is changing people's attitudes, as well as the government's concern and attention of national culture, its form of organization will continue to evolve updates, but does not change the nature of national folk sports, but in organization, financing channels, feedback.

\section{B. National Folk Sport}

National Folk Sport has two dimensions, from the national sports property, the national folk sport is for the modern sports or exotic sports concerned, from the folk sports property point of view, it is for the national folk sports official or mainstream sports in terms of race. Overall, the national folk sport is distinguished from modern mainstream sporting events, native, which embodies the concept of freedom since the sport to survive, these two dimensions constructed properties ethnic folk sporting events. [2] Nowadays folk sports events presented government-led, market and popular participation patterns, such as Hunan Miluo International Dragon Boat Festival, Maqu Assembly, Weifang International Kite Festival and so on. Specific performance is standardized and institutionalized, popular, international five characteristics and mercerization are conducive to the development of national folk heritage and sporting events.

This study suggests that national folk sports refer to the daily life of ordinary people to carry out, provided the nation is created, sports competitions and sports events are related products and services used in the product, the tournament has a certain organization, institutionalization and professionalization. National Folk sporting events are important festival activities, a special event, but also an important cultural heritage of humanity.

\section{National Folk Sports Tourism Destination}

The first view: former National Tourism Administration Weixiao Justice considers sports tourism destination that is able to produce sport tourists travel motivations, and the pursuit of the sum of the various elements of space sports tourism motivation to achieve. [3]

The second view: Wang Feng thinks [3]: sports tourism destination in terms relative to the source region is able to 
meet the needs of a variety of sports and sports tourists housing, transportation, food, travel, shopping, entertainment and other activities place, including a sum of various elements. According to the spatial and range area as large as a country or as small as an attraction, can become a sports tourism destination.

The above definition of the relevant national folk sports, ethnic folk sports events, sports tourism destination suggests that: national folk sports tourism destination is the national folk sports activities as a regional or local tourist attraction that is an important goal, which attracts tourists here for a short stay, sightseeing places. In this study, the "destination" mainly refers to the ethnic folk sports events that are held, such as Weifang International Kite Festival venue, Hunan Miluo Dragon Boat Festival, Chinese Maqu Assembly, Dengfeng Shaolin international Wushu Festival in Dengfeng, Xilin Gol League in Inner Mongolia, Festival that is held in place Gol, Yushu Horse Racing Festival in Yushu and so on.

\section{FEATURE OF OUR NATIONAL FOLK SPORTS TOURISM DESTINATION}

National Folk sports tourism destination is an important part of sports tourism destination, in addition to a basic feature general sports tourism destination, but it also has some characteristics of ethnic folk sporting events. In this study, by combing through the literature review of previous research, it is combined with the definition and characteristics of national folk sports folk sports tourism destination and other characteristics related concepts of national folk sports tourism destination that concludes and summarizes.

\section{A. Complexity Feature of National Folk Sports Tourism Destination}

Based on Supply Chain Management Theory, ethnic folk sports tourism destination by the local government, local people, teams, referees, media, tourists, and many other stakeholders, makes national folk sports event held in the course of their influence by many environmental factors inside and outside the stadium. Meanwhile national folk sport is a tourist destination an important festival activities, with agglomeration effects and sensationalism, the likelihood of the occurrence of unexpected events is large, it has complex features. In 2013, with the Boston Marathon bombings, in 2008, Beijing Olympic Games torch relay in emergencies, and so on, it is worth warning.

\section{B. Characteristics of Scarcity National Folk sports Tourism Destination}

With the resource-based perspective, national folk sports resources are scarce characteristics, which makes it is a tourist destination that also has a scarcity of features. Scarcity of resources is the first principle of economics, all are based on the principle of economic theory, because the scarcity of resources, so that the human economy and all activities need to face the choice of economic theory around this problem, which is to present ideas and arguments. Therefore, national folk sports is an important heritage, tourist destinations important goal of all mankind attraction, its heritage and sustainable development is crucial that the Government is doing my first responsibility.

\section{National, Regional Distinctive Characteristics of National Folk Sports Tourism Destination}

As the saying goes, side soil supports people. Based on the perspective of human geography, ethnic folk sports events is with distinct ethnic, regional characteristics. Like the International Climbing Mount Taishan, the saying Domination, magnificent, imperial dynasties to the closure of the Intertek is with distinct regional characteristics. Maqu County, China Maqu Assembly known as the Yellow River Mother "reservoir" and "Chinese water tower", are the world's most complete primitive ecological wetlands. Located in Gansu, Qinghai and Sichuan provinces at the junction, the first curved portion of the Yellow River is a pure animal husbandry Tibetan county body, which was Tibetan hero King Gesar of activity center. Maqu has rich tourism resources, with Tibetan Buddhist monasteries, stone rock, Kailash Mansarovar and simplicity strong traditional nomadic culture, folk customs and natural landscape dominated widespread, and it was awarded "China's horse racing town", "Tibetan folk songs plays hometown "," mastiff hometown "honorary title, the Panchen Lama wrote:" the world first bends the Yellow River • birthplace of King Gesar prosperity. "Here are the people close to nature; return to the ecological, physical and mental Yen Yang, religion find wins, adventure adventures, a good place is a paradise for eco-tourism.

\section{Characteristics of National Folk Cultural Pluralism Sports Tourism Destination}

Perspective on Cultural, ethnic folk sports is a complex multicultural, making it a tourist destination with diverse cultural characteristics. As Miluo in Hunan Miluo Dragon Boat Festival, culture is the essence of Miluo Dragon Boat Festival; Culture gives it life and vitality to make it enduring. After thousands of years of tradition and evolution, it has been forming a unique dragon boat culture. With the deepening of research Miluo dragon boat race, we can explore the Dragon source vulgar; Qu Yuan appreciates the profound cultural experience romantic passion dragon city, the perception of happiness essence of traditional culture. Hunan Miluo Dragon Boat Race is a multi-cultural complex, which is the source of Hunan culture traditional culture, but it is also in Chinese culture the dragon culture; its core culture is that it is focused on spiritual reflection. Its value is charm that makes those people usually dispersed in an individual manner the activities during the Dragon Boat Festival. With national elite worship and respect, as well as the pursuit of a better spiritual life and longing, they gathered in the Miluo Rive for boat race, View boat, etc., to express and to enjoy each other's friendship and love. 


\section{E. Functional Diversification Feature of National Folk Sports Tourism Destination}

Functional diversification feature of national folk sports tourism destination is mainly from two aspects. On the one hand, the national folk sport itself has a cultural function, enlightenment function, aggregation, entertainment features and aesthetic functions. The second is national folk sports and sports tourism destination tourism destination, sports resort destinations, sports spectators tourist destination, which has a certain correlation between sports adventure tourism destination, athletic tourist destination, folk sports tourism destination, which makes it a functional diversification characteristics. Weifang International Kite Festival will be reflected as fitness, holiday, entertainment, folk viewing and other functions; China Maqu Assembly embodies holiday travel, entertainment, sports, folk viewing and other functions. National Folk Sports tourist destination is to meet the diverse needs of the people, which makes it a strong regional competitiveness.

\section{F. Characteristics of Mutualism National Folk Sports Tourism Destination}

Based on Symbiosis Theory [4], among various fields between China's national folk sports and tourism destination of unit complex individual and the unit, as well as national folk sports tourism destination diverse individuals, in continuous integration development, it reached fit and high degree of unity to achieve national identity, social identity, cultural identity, industry identity and environment. This is our eighth Congress proposed the three countries in the eighth round to determine the "five in one" highly consistent development strategy. Symbiosis degree associated with degree high national folk sports and tourism destination is a mode of mutualism between them, their symbiotic interface is mainly government and markets. Mechanism of national folk sports events affecting tourism destinations are the key elements in this study, which will be detailed in later chapters, this did not need too much spilled ink.

\section{G. National Folk Life Cycle of Sports Tourism Destination}

Tourism is based on the life cycle theory [5], ethnic folk sports tourism destination is no exception, the same should go through exploration: beginning, development, stability, stagnation, decline or revival of six phases. For tourist destinations concerned, to maintain the healthy, sustainable development requires constant innovation resources, integration of resources. First, we organize national folk sport, excavation and protection; the second is the national folk sports and folk culture heritage, aspirant attention and support; the third is the national folk sports and constantly enrich the connotation. This can attract and summon more people come here for sightseeing, tourism, consumption. How to configure resources, integration of resources, mining and protection of resources and its importance is self-evident. To this end, folk sports events now gradually from purely festival events to transition events and cultural importance to the integration of resources, economic and other fields, continue to strengthen and enrich the connotation construction events, focusing on events and promotion, and so on.

\section{CONCLUSION}

National Folk sports tourism destination is the national folk sports activities as a regional or local tourist attraction that is an important goal to attract tourists here for a short stay in the sightseeing places.

China's national folk sports tourism destination is with complex characteristics, characteristics of scarcity, national and regional characteristics, cultural diversity characteristics, functional diversification characteristics, mutualism features, as well as tourism life cycle characteristics.

\section{ACKNOWLEDGEMENTS:}

Fund: Fund National Social Science Fund Project "affects our national folk sports tourism destination research" (12CTY021)

\section{REFERENCES:}

[1] Bai Jinxiang. Ethnic folk sports editor [M] Beijing: Higher Education Press, 2010.7: 1-14.

[2] Li Yanchao, Yu Zhongyu. Dry ethnic people ask positioning sports research, content and implementation [J] Sports Science, 2011,31 (3): 22-29.

[3] Wang Hui. Competitive sports tourism destination in Hainan research [D] Haikou: Master's thesis, Hainan Normal University, 2013,4: 16.

[4]WangZhenZhen, Bao Xinghua. Status quo industrial symbiosis theory development and applied research [4] [J] East China Economic Management, 2012,26 (10): 131-135.

[5] Yu Shuwei. Book "Tourism Area Life Cycle Theory" Fully On Discussion with Young Forest [J] Tourism Tribune, 1997 (1): 32-37. 